\title{
The Role of Nurses in the Systemic Therapy of Mental Diseases
}

\section{Koukourikos Konstantinos}

Nursing Department, Alexander Technological Educational Institute of Thessaloniki, Thessaloniki, Greece

\section{Email address:}

kokaea@yahoo.gr (K. Koukourikos)

\section{To cite this article:}

Koukourikos Konstantinos. The Role of Nurses in the Systemic Therapy of Mental Diseases. American Journal of Nursing Science. Special Issue: Mental Health Care: Aspects, Challenges and Perspectives. Vol. 4, No. 2-1, 2015, pp. 84-87. doi: 10.11648/j.ajns.s.2015040201.25

\begin{abstract}
Introduction: Systemic therapy is an approach to helping people with psychological difficulties which is radically different from other therapies. It does not see its work as being to cure mental illnesses that reside within individuals, but to help people to mobilize the strengths of their relationships so as to make disturbing symptoms less problematic. Aim: The objective of this retrospective study is to highlight the role of nurses in the safe and successful application of systemic therapy and in the formation of the therapeutic relationship. Material and methods: The sample consisted of recent articles (2000-2014) on the topic, found mainly in the electronic database Medline, the Greek Academic Libraries Link (HEAL-Link) and through search engine "Google scholar". Results: The use of systemic thinking presupposes acknowledgement of the fact that living creatures directly depend on their external environment. A nurse also plays a part in the creation of the reality seen. A nurse does not discover the truth, but the things he/she sees constitute products of his/her own observations about family. Conclusions: Systemic therapy is a form of psychotherapy. It addresses behavior and psychological symptoms within the context of people's day to day lives and interpersonal relations and interactions. The key guiding principle in systemic therapy is the focus on the system rather than the individual.
\end{abstract}

Keywords: Systemic Psychology, Systemic Therapy, Systemic Family and Couples Therapy, Nurse

\section{Introduction}

Throughout the history of Psychiatry, several theoretical approaches to the development of personality and psychopathology have been developed. These different viewpoints aim at making a person's behavior and functioning understandable in his/her functioning context [1] [2].

Systemic theory is an approach studying people inside a group, in the system where they belong to, as well as in the mega-systems surrounding them. Systemic theory was based on the general systems theory [3]. This method is quite new, since it has its roots after 1940. This shows us that, even today, it is evolving and changing in the course of time [4]. It is a theory which was initially developed in the field of engineering, and was later applied to other sciences as well, including economics, biology, and computer science. It has offered an alternative to this dead end, showing how an intentional behavior appears as a property of a system consisting of simple elements, which are not characterized, however, by intention [5]. Based on this belief, the systemic theory was also applied to the field of psychotherapy and counselling, treating human "problems" as inherent and dynamic properties of social systems, especially of family, rather than as a characteristic of the people who constitute such social system [6].

According to Systemics, we are born and we grow within strongly influential groups, where the most dominant group is family. These groups characterize and define us. Certainly, every one of us depends on "horizontal" relationships, i.e., those that develop in the present time, as well as on "vertical" relationships, i.e., those of the smaller or larger systems where we belong to [3], [5].

In the field of health, the systemic approach has been adopted by many mental health professionals, including physicians, nurses, speech therapists, psychologists, social workers, occupational therapists, health visitors, who are increasingly cooperating in an interdisciplinary way, in order to holistically treat every patient, laying emphasis on their interaction with their family, hospital, social, and cultural environment [7].

Nursing theories advocate the holistic treatment of patients, with a particular emphasis laid on the relationship among 
persons, environment, and health. Such nursing theories and models include Betty Neuman's systems model, Sister Callista Roy's adaptation model, Madeleine Leininger's transcultural approach to health and disease. [8].

A new medical approach has been developed in the USA, which focuses on families, whenever one of their members suffers from a health problem (Family Systems Medicine). This approach presupposes a close cooperation between physicians and family therapists, e.g., nurses, social workers, since a large number of health professionals highlight the decisive role that family plays in the occurrence and treatment of medical conditions, e.g., psychopathological disorders [9].

The possibility of a patient telling his/her personal story is of key importance in the systemic therapy procedure, where the objective of the therapy is to reconstruct a number of stories, so that a person may be led to a different perception of problems and to some alternative solutions. Thus, through narration to an appropriately trained listener, a person can organize his/her experiences into speech, recognize the losses he/she is experiencing because of his/her illness, discover the reserves he/she has to face the challenges in life, and reconstruct a life story described by cohesion [10].

\section{Aim}

This retrospective study highlights the role of Nursing, especially that of nurses, in the safe and successful application of systemic therapy and the formation of the therapeutic relationship.

\section{Material and Methods}

The materials of this study consisted of some recent articles on this issue, which were mostly found in Medline electronic database, in the Hellenic Academic Libraries Link (HEAL-Link), and also through "Google scholar" search engine using the key words: Systemic psychology, systemic therapy systemic family and couples therapy, nurse. The exclusion criterion of the articles was language, other than English and Greek.

\section{Systemic Therapy}

First of all, to carry out a systemic therapy means to think in a systemic way, in order to work in any therapeutic context: person, family, pair and group. [11]. In addition, it means to enter, along with the client, into a complex of ideas, emotions, and important persons, which are connected in a circle and are investigated by both interlocutors, through language [12], [13].

Since the rationale of the systemic therapist is based on the idea of complementarity and on the priority given to asking questions, rather than to giving answers, this results, in the course of time, in transmitting a way of connecting things and persons, facts and meanings to the recipient, such that he/she can be liberated from the rigid viewpoint he/she has developed for himself/herself and for the reality surrounding him/her [3] [14].

Thus, the treated person can expand and deepen his/her sensitivity and become open to the possibility of experimenting and seeing the facts and stories of his/her life through a wider perspective. Therefore, through the prism of narrative description, we might say that the client is released from a story, which has become inflexible and causes pain, and may enter into a new story, with more truth and autonomy [15]. The systemic view lays stress on the consideration of problems beyond what the persons considers as complicated and associated. It considers the concepts of entirety, relationship, and homeostasis as central concepts. According to the systemic theory, entirety means that the elements or parts of a system form an entity, which is larger than the individual parts added together. According to this theory, no system can be adequately understood or fully investigated if it has not been separated from the parts that constitute it [16].

In some cases, when nature and the feeling of emergency of any problems appearing (e.g., phobic, or obsessive, compulsive behavior) require certain typical strategic systemic interventions, we confine ourselves to working with this particular problem, in a few sessions, without entering into an investigation of the client's history in depth [17].

The nurse-therapist puts investigation, thinking, and emotion, in the centre of the therapeutic scene, with the help of multiple theoretical lenses (filters), which are derived from his/her practical experience and theoretical research [16], [18].

\section{Nursing and Systemic Therapy}

A mental health professional trainee and, in this case, a nurse training in systemic therapy, must learn a model and, as long as he/she is learning it, it is necessary that he/she strictly follows its principles, methodology, and techniques in the context of training, in order to avoid any confusion. However, as soon as the model has been learned, tested and assimilated, one can subsequently learn other models as well, more or less skillfully [1], [5].

Therefore, this new knowledge will inevitably contribute to the enrichment of a nurse's thinking and practice. Gradually, as the trainee becomes familiar with the model and practices more and more, he/she will develop skill in its application and will eventually develop his/her own autonomy and creativity [19].

Another feature of therapy is the active participation of the treated person in collaboration with the therapist, in its formation and establishment, and in the mutual negotiation of the goals of therapy and of the way they will be achieved. Finally, the development of therapy must suffer some setbacks, whose solution will lead to a successful therapy. Therapy as a cooperative relationship, in general, does not only provide the treated person with a safe environment to 
explore himself/herself, but the process of development of this relationship by itself may reflect the most important relational problems that the treated person is facing or has already faced [7]. Thus, the therapeutic alliance depends on the cooperation between therapist and treated person and, depending on the needs and skills of the therapist and those of the treated person, it facilitates the formation of a therapy contract, which covers the whole range of the therapeutic procedure. The therapist must ensure certain conditions for the treated person, which will make him/her feel safe, protected and accepted, while the treated person must be sincere and genuine in the way he/she expresses his/her thoughts and feelings during the therapy [6].

The necessary and adequate conditions for a successful therapy are met through the therapeutic intervention. Thus, what is of importance is the quality of the therapeutic alliance, while the cooperation between therapist and treated person results naturally from the necessary and adequate conditions, rather than from the implementation of certain psychotherapeutic techniques [20], [21],[22].

Therefore, the dimensions of the role of nursing in systemic therapy, especially in the systemic therapy of the mentally ill, are summarized in the following points [7], [11]:

- Appropriate training, so that the nurse may assume the role of therapist: modern scientific knowledge (Training in Psychotherapy, Psychodynamic Psychiatry, Shortterm Personal Psychoanalytic Psychotherapy, Group Therapy, Family Therapy, and Couples Therapy in Mental Health Centers, and Intervention to large human systems - Schools, Institutes).

- A nurse can also be trained in psychodrama for at least 4 years (sociodrama, "role playing"). In this field, an understanding of the different types of family systems, as a framework of complex interactions, where interpersonal relations are created and develop, is attempted. Through supervision and practice of psychodrama, the trainees learn how to identify and describe the existing difficulties and malfunctions in a certain family system, and propose certain changes and interventions they consider that must be attempted, in order to restore the good functioning of the family [11].

What is considered important is [7], [11]:

a) To understand the family as a system

b) To understand the different types of family systems

c) To understand the family system in the context of interaction, where other systems and subsystems operate as well

d) To understand the variety of approaches to family therapy

e) That, in the context of supervision, training nurses are able to describe a family system they have examined, are able to discuss the changes required in the system and the interventions they would make, while citing the thinking procedure of these interventions

f) That they are able to incorporate the systemic theory into organizations, role theory, family therapy, and teamwork.

\section{Conclusion}

In our times, modern people face several difficulties which disturb their mental well-being. Tackling the above mentioned problems must be done holistically and can be achieved by systemic thinking and theory.

In addition, the use of systemic thinking presupposes the acknowledgement of the fact that living creatures directly depend on their external environment. Moreover, many principles that are valid in biology are identified and transferred to the family system. Concepts including homeostasis and feedback, play a crucial role in the analysis of the family system.

Finally, nurses are no longer passive observers of reality and family. They also play a role in the creation of reality observed. They do not discover the truth, but the things they see, constitute products of their own observations on family. Their role is changing and becomes more intrusive in the system, through their participation in it.

\section{References}

[1] Lucksted, A., McFarlane, W., Downing, D. and Dixon, L. (2012). Recent Developments in Family Psychoeducation as an Evidence-Based Practice. Journal of Marital and Family Therapy, 38(1):101-121

[2] Karamat A. R.. (2004). Bilingualism and systemic psychotherapy: some formulations and explorations. Journal of Family Therapy, 26( 4), :340-357

[3] Midgley, G. (Ed.). (2003). Systems thinking. London: Sage Publications.

[4] Carr, A. (2011). Thematic review of family therapy journals 2010. Journal of Family Therapy, 33(4): 429-447.

[5] Montesano A, Feixas G, Muñoz D, Compañ V. (2014). Systemic couple therapy for dysthymia. Psychotherapy, 51(1):30-40

[6] Winek L Jon. (2010). Systemic Family Therapy: From Theory to Practice. Thousand Oaks, CA: Sage Publications, Inc

[7] Papadioti V, Softas-Nall, L. (2006). Family - Systemic Therapy: Basic approaches, theoretical views, and practical application. ( $2^{\text {nd }}$ Ed.) Athens: Ellinika Grammata ( in greek)

[8] Woodson, C., Softas-Nall, L. \& Johnson, B. (2012). Family Chaos and Readiness to Change Problematic Alcohol Use. Journal of Human Social Sciences, 12 (2): 19-28.

[9] Kourkouta L, Barsamidis K, Lavdaniti M. (2013) Communication skills during the clinical examination of the patients. Progress in Health Sciences, 3(1); 119-122.

[10] Rana D, Upton D. (2010). Psychology for nurses. Athens: Paschalidis Editions ( in greek)

[11] Pote H., Stratton P., Cottrell D., Shapiro D., Boston P. (2003). Systemic family therapy can be manualized: research process and findings. Journal of Family Therapy , 25( 3): 236-262,

[12] Flaskas C, (2007). 'Systemic and psychoanalytic ideas: using knowledges in social work'. Journal of Social Work Practice, 21(2), pp. $131-147$ 
[13] Satir, V. (1992). Human communication. Translation: Dourga A. Athens: Diodos (in greek)

[14] Tossavainen K, Turunen H, Jakonen S, Tupala M, Vertio H, (2004). "School nurses as health counsellors in Finnish ENHPS schools", Health Education, 104 ( 1) : 33 - 44

[15] Taylor C., Lillis C., Le Mone P. (2006) Fundamental Principles of Nursing. Athens: Paschalidis Editions ( in greek)

[16] Carr A. (2009).The effectiveness of family therapy and systemic interventions for adult-focused problems. Journal of Family Therapy, 31(1): 46-74,

[17] Flaskas, C. (2005a) Psychoanalytic ideas and systemic family therapy: revisiting the question 'why bother?' Australia New Zealand Journal of Family Therapy, 26(3): 125-134

[18] Kourkouta L., Papathanasiou I. V. (2014) Communication in Nursing Practice. Mater Socio med, 26(1): 66-68.
[19] Papathanasiou I V, Kleisiaris C F. Fradelos E C, Kakou K, Kourkouta L. (2014). Critical Thinking: The Development of an Essential Skill for Nursing Students. ACTA INFORM MED, 22(4): 283-286.

[20] Carr, A. (2006). Family Therapy: Concepts, Process and Practice. 2nd Ed. Chichester: John Wiley \& Sons.

[21] Kourkouta, L.I. (2010). Diagnostic Nursing Approach. Athens: Paschalidis Ed.

[22] Lemmens G, Eisler I, Migerode L, Heireman M, Demyttenaere K. (2007). Family discussion group therapy for major depression: a brief systemic multi-family group intervention for hospitalized patients and their family members. Journal of Family Therapy, 29(1): 49-68. 